\title{
Desain Arsitektur Sistem Parkir Otomatis Dengan Arduino Uno Pada Scientia Residences Tangerang
}

\author{
Aris $^{1}$, Ferry Ardiyanto $^{2}$, Erika Septiyanti ${ }^{3}$ \\ ${ }^{1}$ Program Studi Teknik Informatika Universitas Raharja, \\ ${ }^{2}$ Program Studi Sistem Informasi Universitas Raharja \\ ${ }^{3}$ Program Studi manajemen Informatika Universitas Raharja \\ E-mail: "19aris@raharja.info, ${ }^{2}$ ferryardiyanto@ raharja.info, ${ }^{3}$ erika.septiyanti@ raharja.info
}

\begin{abstract}
Abstrak
Sistem parkir otomatis sangat diperlukan di dalam mengelola perparkiran dan untuk memudahkan di dalam pengelolaan area parkir. Sistem perparkiran yang ada pada Scientia Residences Tangerang masih dilakukan dengan cara memasukkan nomor kendaraan ke komputer oleh operator, kemudian melakukan pencetakan, ini berarti tiket parkir yang diberikan kepada penghuni dan tamu Scientia Residence Tangerang berupa kertas parkir yang isinya nomor kendaraan dan data waktu masuknya kendaraan ke dalam residences tersebut. Permasalahan terjadi disaat petugas parkir melakukan transaksi parkirnya tersebut yang rentan mengalami kesalahan penginputan data dan kesalahan lainnya. Pembuatan sistem parkir yang otomatis merupakan pilihan terbaik untuk memberi solusi dari permasalahan yang ada. Hasil akhir penelitian ini berupa desain arsitektur sistem parkir otomatis yang menggunakan Arduino Uno untuk diimplementasikan pada Scientia Residences Tangerang dengan tujuan mengefisienkan waktu dan meningkatkan kinerja petugas parkir residences tersebut.
\end{abstract}

Kata Kunci : Desain Arsitektur, Sistem Parkir Otomatis, Arduino Uno.

\begin{abstract}
Automated parking systems are indispensable in managing parking and to facilitate the management of parking areas. The existing parking system at Scientia Residences Tangerang is still carried out by entering the vehicle number into the computer by the operator, then printing, this means that the parking ticket given to residents and guests of Scientia Residence Tangerang is in the form of parking paper containing the vehicle number and data when the vehicle entered the parking lot. in these residences. Problems occur when parking attendants carry out parking transactions which are prone to data input errors and other errors. Making an automatic parking system is the best choice to provide solutions to existing problems. The final result of this research is the architectural design of an automatic parking system that uses Arduino Uno to be implemented at Scientia Residences Tangerang with the aim of saving time and improving the performance of the parking attendants of the residences.
\end{abstract}

Keywords: Architectural Design, Automatic Parking System, Arduino Uno.

\section{PENDAHULUAN}

Sistem parkir otomatis sangat diperlukan di dalam mengelola perparkiran dan untuk memudahkan di dalam pengelolaan area parkir. Sistem perparkiran yang ada pada Scientia Residences Tangerang masih dilakukan dengan cara memasukkan nomor kendaraan ke komputer oleh operator, kemudian melakukan pencetakan, ini berarti tiket parkir yang diberikan kepada penghuni dan tamu Scientia Residence Tangerang berupa kertas parkir yang isinya nomor kendaraan dan data waktu masuknya kendaraan ke dalam residences tersebut. 
Permasalahan terjadi disaat petugas parkir melakukan transaksi parkirnya tersebut yang rentan mengalami kesalahan penginputan data dan kesalahan lainnya. Pembuatan sistem parkir yang otomatis merupakan pilihan terbaik untuk memberi solusi dari permasalahan yang ada. Hasil akhir penelitian ini berupa desain arsitektur sistem parkir otomatis yang menggunakan Arduino Uno untuk diimplementasikan pada Scientia Residences Tangerang dengan tujuan mengefisienkan waktu dan meningkatkan kinerja petugas parkir residences tersebut.

\section{PERMASALAHAN}

Permasalahan saat ini antara lain : 1) Bagaimana sistem parkir yang berjalan saat ini Pada Scientia Residences Tangerang? 2) Kendala apa saja yang sering dihadapi dalam sistem servis parkir ini? 3) Bagaimanakah cara yang tepat agar sistem parkir ini berjalan dengan efektif dan efisien? Ketiga hal ini harus dicarikan solusi pemecahan masalahnya agar sistem parkir pada Scientia residences Tangerang dapat teratur dan tersistematis.

\section{METODOLOGI PENELITIAN}

Metodologi penelitian dapat digambarkan pada Diagram Alir dibawah ini :

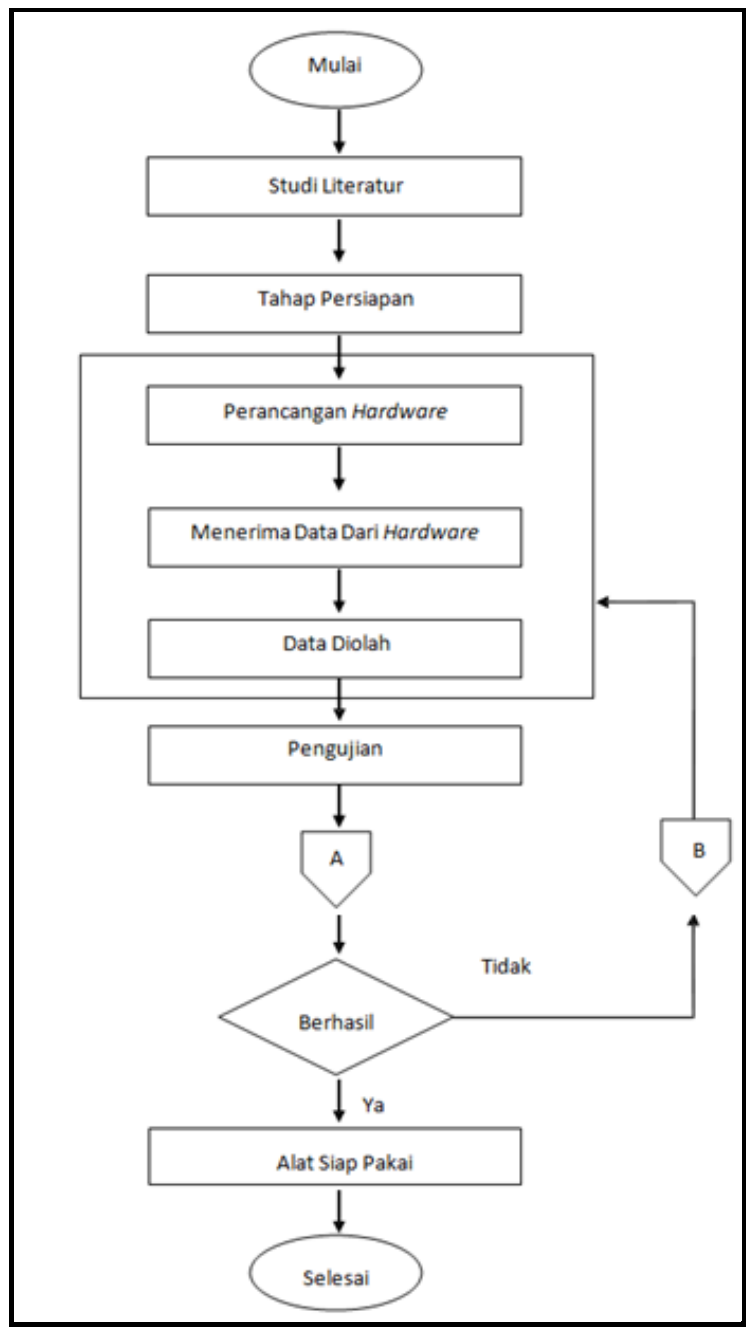

Gambar 1 Gambar Diagram Alir Desain Arsitektur Tools Sistem Parkir 


\section{HASIL DAN PEMBAHASAN}

\section{Desain Arsitektur Tools Sistem Parkir} bawah ini :

Untuk desain arsitektur sistem parkir menggunakan alat/tools yang digambarkan di

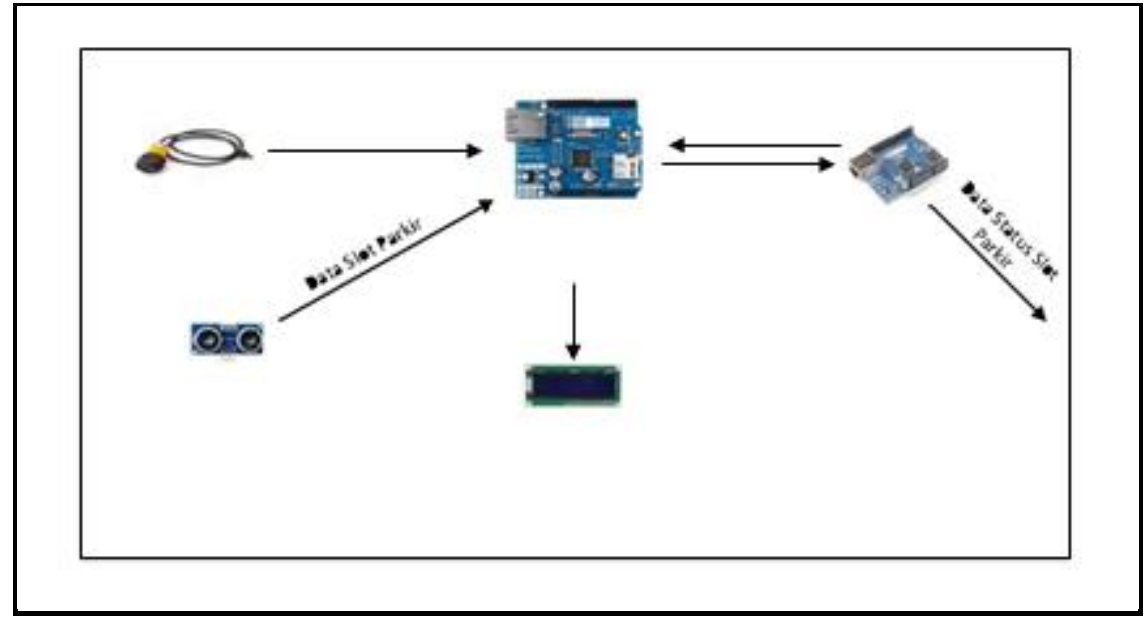

Gambar 2. Desain Arsitektur Tools Sistem Parkir

Dibawah ini penjelasan mengenai gambar 2. Desain Arsitektur Tools Sistem Parkir diatas :

1. Sensor Infrared, berfungsi sebagai alat pendeteksi kendaraan masuk dan dikirimkan ke Arduino uno agar dapat mengelola data kendaraan masuk

2. Sensor Ultrasonik, berfungsi untuk mendapatkan data tempat parkir secara realtime yang akan dikirim ke Arduino untuk dikelola sebagai data tempat parkir yang sudah terisi maupun data tempat parkir yang tersedia.

3. Arduino Uno, berfungsi sebagai pusat kendali utama pengumpulan data- data yang dideteksi oleh sensor dan mengirimkan data-data yang telah dihasilkan oleh sensor tersebut ke dalam server.

4. LCD Display, berfungsi untuk memberikan informasi navigasi kepada user yang sedang mencari tempat parkir dan memberikan informasi detail tempat parkir yang tersedia dan sudah terisi

5. Ethernet Shield, berfungsi sebagai papan penyedia layanan ethernet. Papan ethernet tersebut akan menjembatani Arduino agar dapat terhubung dengan jaringan LAN yang terkoneksi melalui Router.

6. Komputer, berfungsi untuk monitoring tempat parkir.

\section{Analisa Komunikasi Data Sistem}

Untuk analisa Komunikasi Data Sistem tertuang pada gambar 3 dibawah ini : 


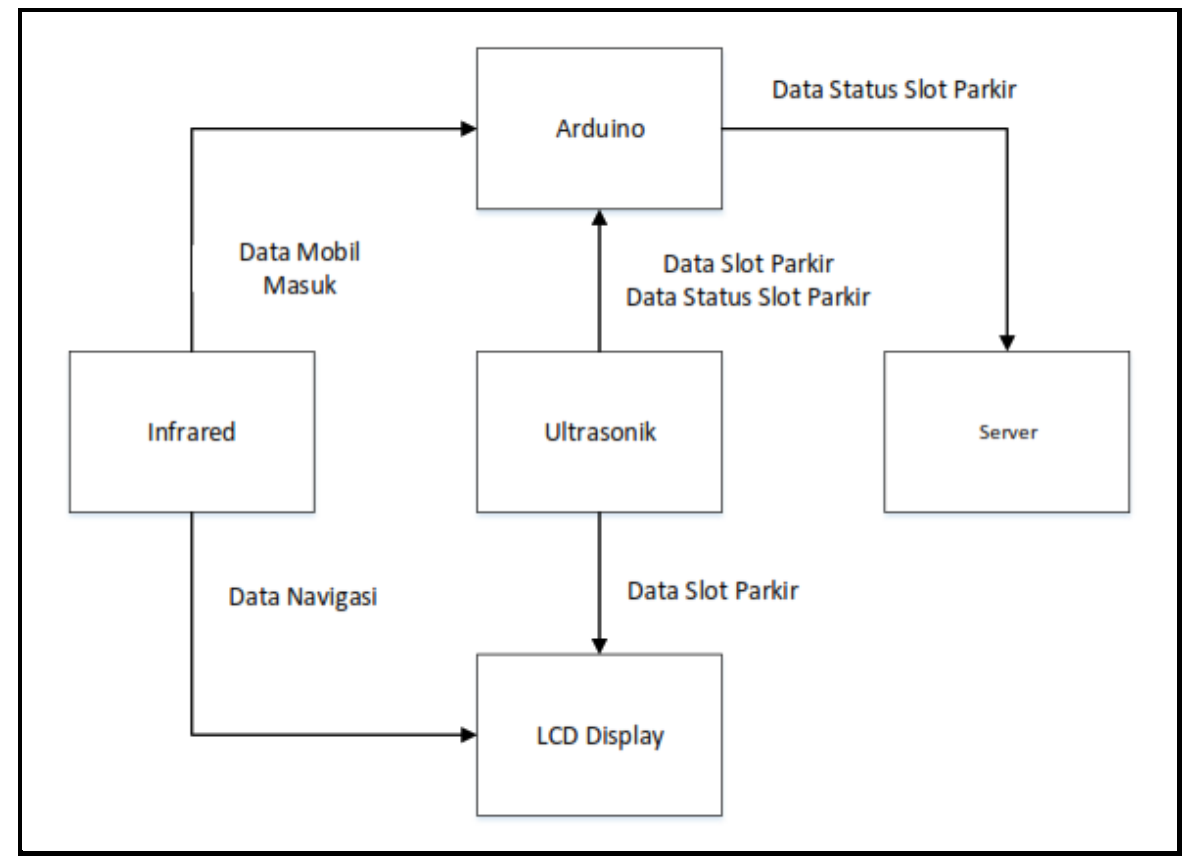

Gambar 3. Analisa Komunikasi Data Sistem

Keterangan :

1. Untuk dapat masuk kedalam Scientia Residences Tangerang, penghuni dan tamu menggunakan kartu akses berbasis RFID.

2. Untuk tag RFID ini menggunakan ID-12 yang bekerja pada frekuensi 125-134 Khz.

3. Untuk Komunikasi dengan komputer/PC menggunakan hubungan kabel UTP dengan model Cross.

4. Untuk Komunikasi dari LCD ke Mikro ini menggunakan Kabel Serial.

5. Untuk Komunikasi pengiriman data dari kamera ke komputer/PC menggunakan kabel yang panjangnya kurang lebih 1 meter.

6. Untuk Komunikasi pengiriman data dari komputer/PC ke Mikrokontroler menggunakan kabel serial yang panjangnya kurang lebih $30 \mathrm{~cm}$.

7. Untuk Sensor LDR mampu menangkap pancaran cahaya dari sensor LED radius kurang lebih $30 \mathrm{~cm}$.

8. Untuk Motor Servo memiliki kemampuan berputar sampai dengan $360^{\circ}$ dengan posisi palang pintu yang menggunakan sudut $0^{\circ}-90^{\circ}$.

\section{Spesifikasi Sistem Blok Diagram}

Untuk spesifikasi Sistem Blok Diagram digambarkan di bawah ini : 


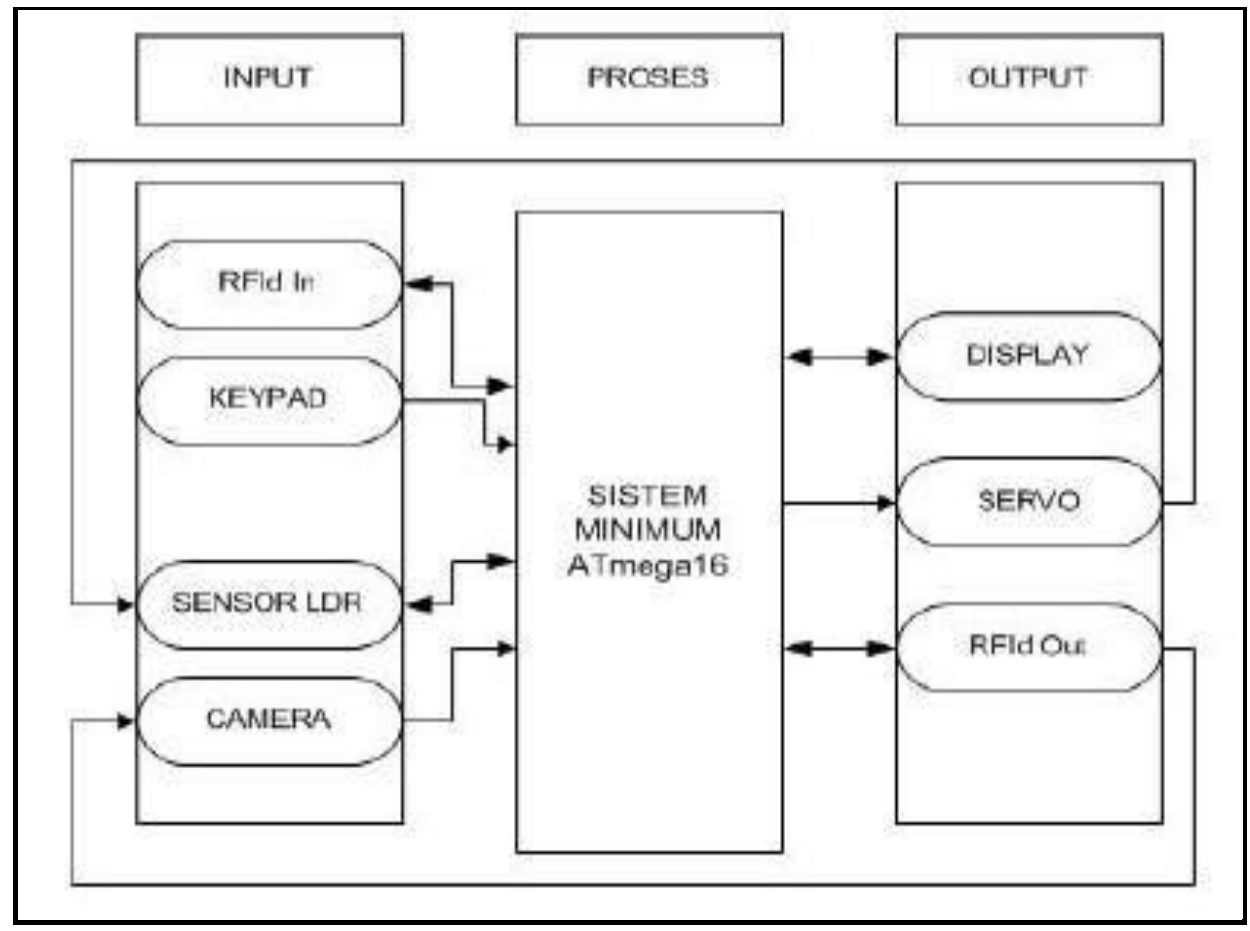

Gambar 4. Spesifikasi Sistem Blok Diagram

Keterangan gambar 4 diatas :

1. RFID yang digunakan untuk memeriksa data member terdaftar atau tidak pada area parkir tersebut.

2. Numpad yang digunakan untuk memilih posisi tempat parkir pada LCD di pintu masuk

3. Sensor LDR dan LED sensor LDR yang digunakan untuk memberi instruksi pada servo yang pada saat kendaraan sebelum ataupun sesudah melewati palang pintu, dan LED yang berguna untuk memberikan informasi kepada pengendara mengenai status slot parkir yang kosong ataupun terisi

Bagian Output Sistem ini terdiri dari :

1. Servo yang digunakan untuk memberikan akses masuk ke pengendara, Servo ini akan terbuka jika pengendara sudah tag kartu RFID dan akan menutup setelah sensor LDR mengirim data kendaraan sudah melewati palang pintu

2. Display yang digunakan untuk memberikan informasi kepada user mengenai slot parkir

3. Camera File yang digunakan untuk mengcapture bagian plat nomor kendaraan sebagai data pelengkap dari RFID.

Gambar 5 dibawah ini merupakan gambar Arsitektur Denah Parkir : 


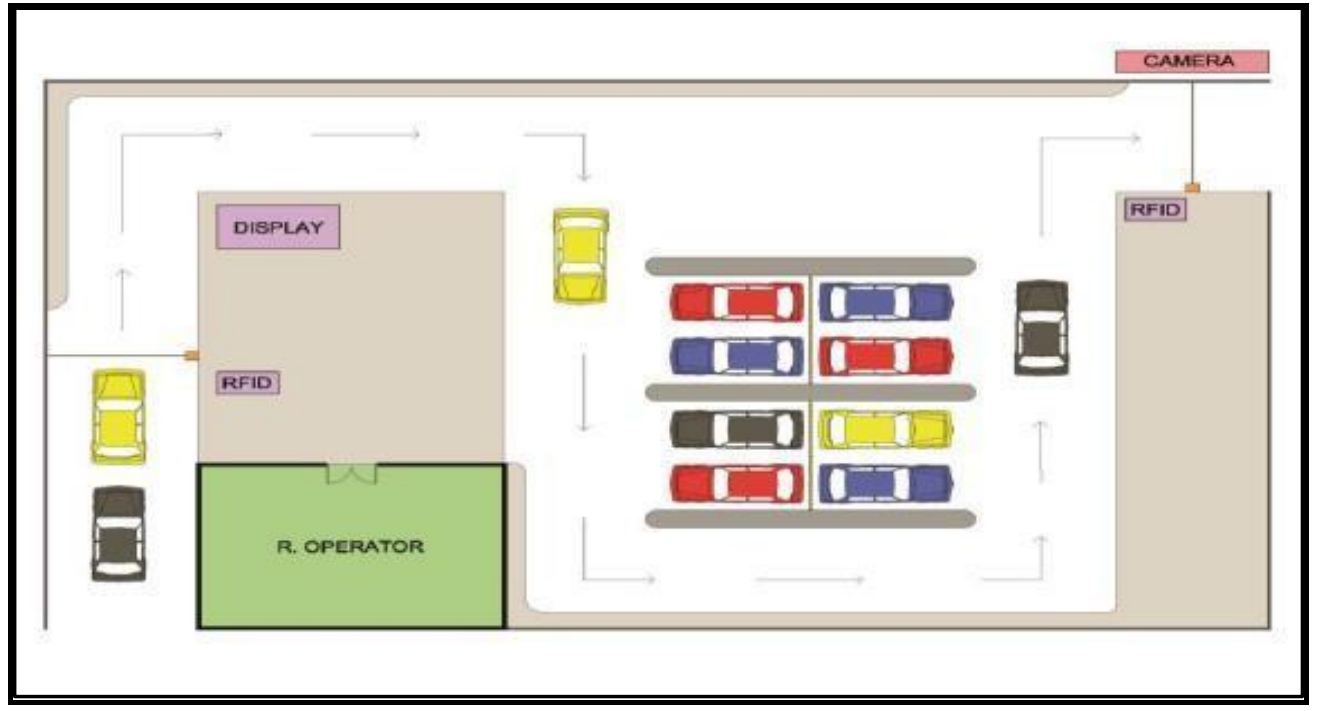

Gambar 5. Arsitektur Denah Parkir

Keterangan gambar 5 diatas :

a. Pada desain arsitekturnya menggunakan software/perangkat lunak yang menggunakan bahasa Atmel studio.

b. Software/Perangkat lunak yang direalisasikan menggunakan sensor LDR, RFID, Numpad, Servo, Display LCD dan Mikrokontroler.

c. Software/Perangkat lunak didesain untuk dapat melakukan pemilihan posisi parkir dan untuk mencatat segala informasi mengenai pengakses parkir yang kemudian disimpan ke dalam database.

d. Untuk Proses download programming ke Mikrokontrolernya menggunakan USB Flasher.

\section{Kebutuhan Hardware/Perangkat Keras}

Untuk kebutuhan Hardware/Perangkat Keras Alat pendeteksi dijelaskan pada tabel spesifikasi di bawah ini :

Tabel 1. Tabel Spesifikasi Alat Pendeteksi

\begin{tabular}{|l|l|}
\hline Hardware & Detail \\
\hline Arduino Uno & ATMega328 \\
\hline Ethernet Shield & Wiznet W5100 \\
\hline Sensor Ultrasonik & HC - SR04 \\
\hline Router & TL-MR3020 \\
\hline Modem & $4 \mathrm{G}-\mathrm{E} 3276$ \\
\hline LCD Display & $16 \times 2$ \\
\hline Breadboard & 400 Tie Point \\
\hline Sensor Infrared & E18-D50NK \\
\hline
\end{tabular}

Untuk kebutuhan Hardware/Perangkat Keras Komputer Server dijelaskan pada tabel spesifikasi di bawah ini : 
Tabel 2. Spesifikasi Komputer Server

\begin{tabular}{|l|l|}
\hline Hardware & Detail \\
\hline Processor & Intel Core 2 Duo \\
\hline RAM & $2 \mathrm{~GB}$ \\
\hline Harddisk & $250 \mathrm{~GB}$ \\
\hline VGA & On-Board \\
\hline
\end{tabular}

Untuk kebutuhan Hardware/Perangkat Keras Komputer Client dijelaskan pada tabel spesifikasi di bawah ini :

Tabel 3. Spesifikasi Komputer Client

\begin{tabular}{|l|l|}
\hline Hardware & Detail \\
\hline Processor & Intel Core 2 Duo \\
\hline RAM & $2 \mathrm{~GB}$ \\
\hline Harddisk & $250 \mathrm{~GB}$ \\
\hline VGA & On-Board \\
\hline
\end{tabular}

Untuk kebutuhan Hardware/Perangkat Keras Perangkat Input \& Output dijelaskan pada tabel spesifikasi di bawah ini :

Tabel 4. Perangkat Input \& Output

\begin{tabular}{|l|l|}
\hline No & Perangkat I/O \\
\hline 1. & Mouse \\
\hline 2. & Keyboard \\
\hline 3. & Monitor \\
\hline 4. & Printer \\
\hline
\end{tabular}

Untuk kebutuhan Hardware/Perangkat Keras yang dibutuhkan untuk membangun desain arsitektur sistem parkir otomatis ini dijelaskan pada tabel spesifikasi di bawah ini :

Tabel 5. Spesifikasi yang dibutuhkan

\begin{tabular}{|l|l|}
\hline Hardware & Detail \\
\hline Processor & Intel Core 2 Duo \\
\hline RAM & $2 \mathrm{~GB}$ \\
\hline Harddisk & $250 \mathrm{~GB}$ \\
\hline VGA & On-Board \\
\hline
\end{tabular}

\section{Penggambaran Diagram UML}

a. Use Case Diagram

Untuk Use Case diagram digambarkan seperti dibawah ini : 


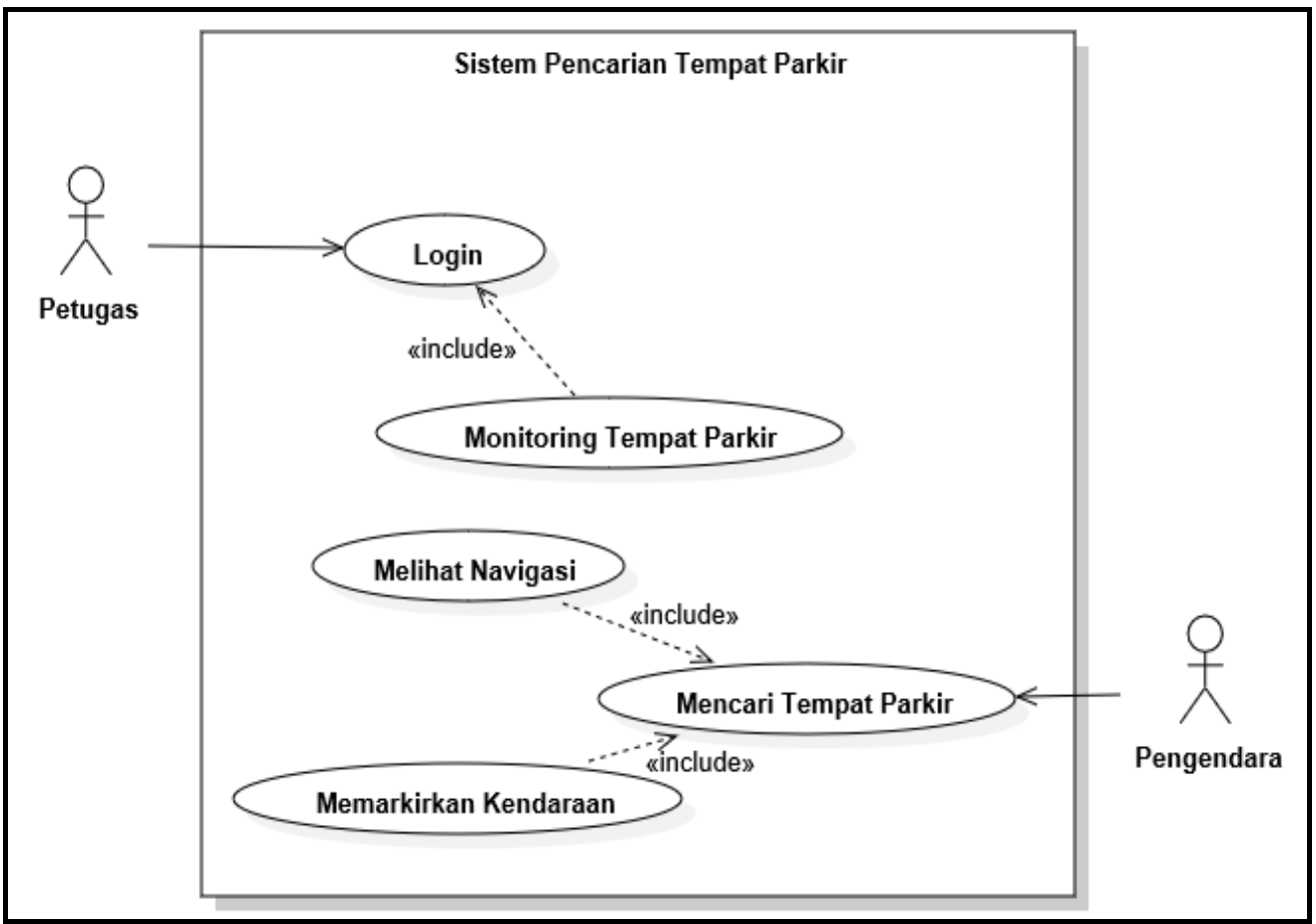

Gambar 6. Use Case Diagram Sistem

Tabel 6. Deskripsi Actor dan Use Case

\begin{tabular}{|c|c|c|}
\hline No & Actor & Deskripsi \\
\hline 1 & Petugas & Karyawan secure parking yang memonitoring tempat parkir \\
\hline 2 & Pengendara & $\begin{array}{l}\text { Mengikuti navigasi dan memarkirkan mobil di tempat yang } \\
\text { telah disediakan oleh sistem }\end{array}$ \\
\hline No & Use Case & Deskripsi \\
\hline 1 & Login & Melakukan login di aplikasi pengelolaan data tempat parkir \\
\hline 2 & $\begin{array}{l}\text { Monitoring Tempat } \\
\text { Parkir }\end{array}$ & Menampilkan Kondisi Tempat Parkir \\
\hline 3 & Memarkirkan Mobil & $\begin{array}{l}\text { User memarkirkan mobil sesuai tempat yang di lihat pada } \\
\text { navigasi }\end{array}$ \\
\hline 4 & Melihat navigasi & User melihat navigasi untuk mendapatkan tempat parkir \\
\hline
\end{tabular}

\section{b. Activity Diagram} bawah ini :

Untuk Activity diagram terbagi menjadi 4 activity seperti yang tergambar di

1. Activity Diagram untuk Login

Activity diagram untuk Login ini menjelaskan mengenai alur kerja didalam melakukan monitor status alat elektronik. 


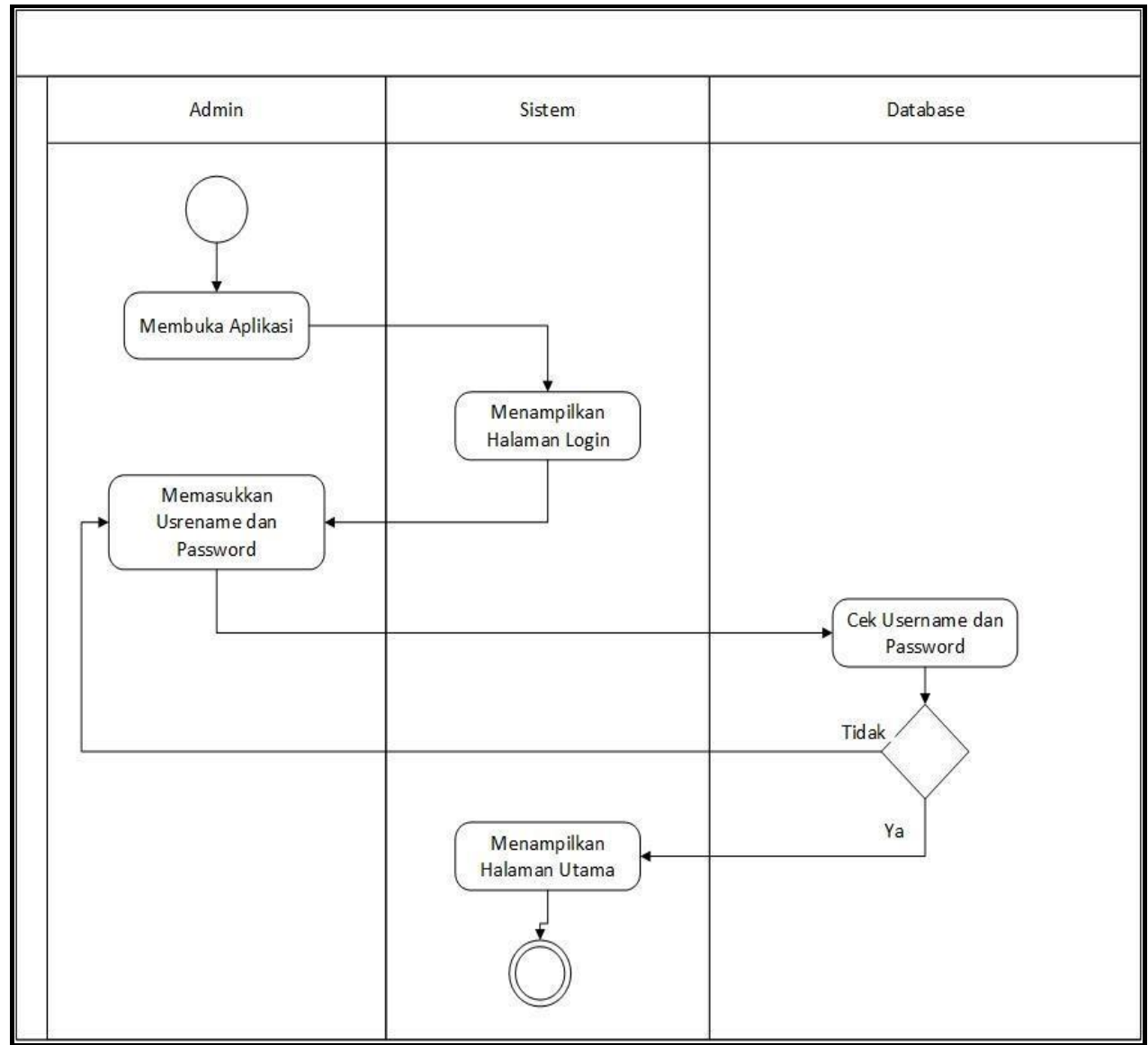

Gambar 7. Activity Diagram Login

2. Activity Diagram Monitoring Tempat Parkir

Untuk Activity diagram monitoring tempat parkir digambarkan sebagai berikut : 


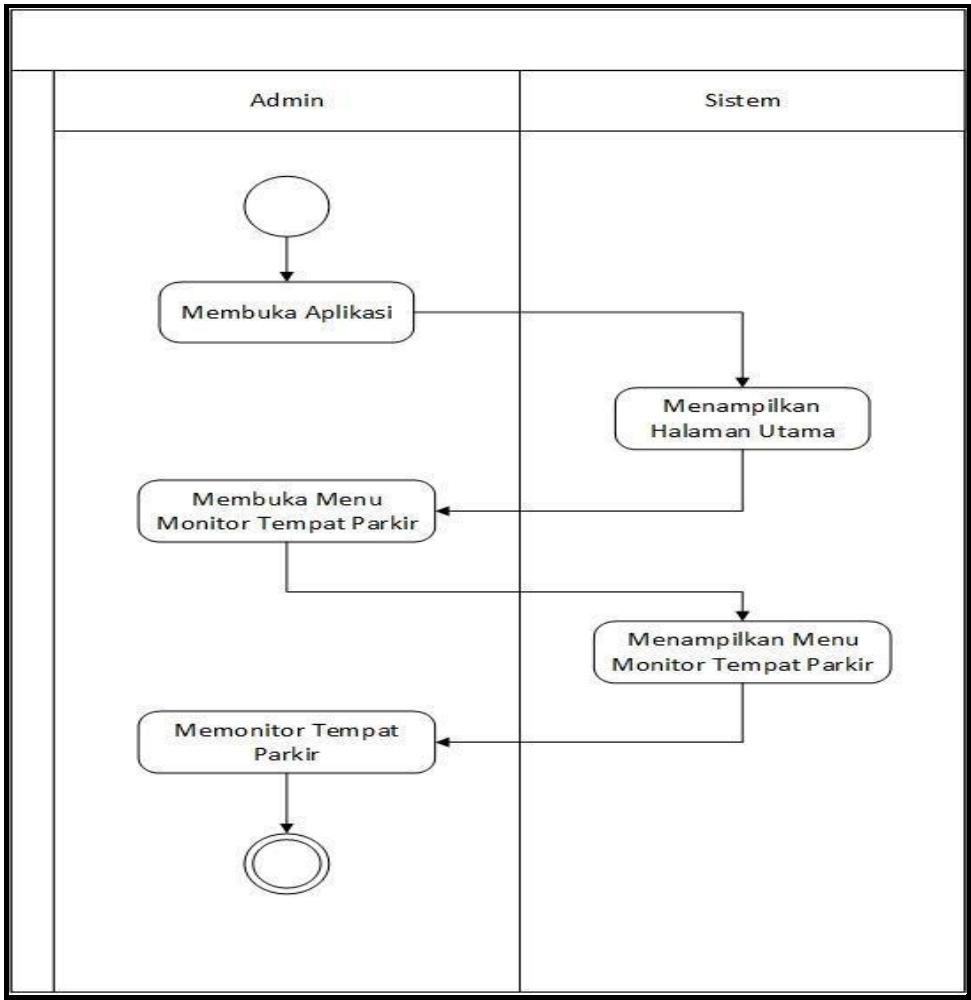

Gambar 8. Activity Diagram Monitoring Tempat Parkir

3. Activity Diagram Memarkirkan Mobil

Untuk Activity diagram memarkirkan mobil digambarkan sebagai berikut :

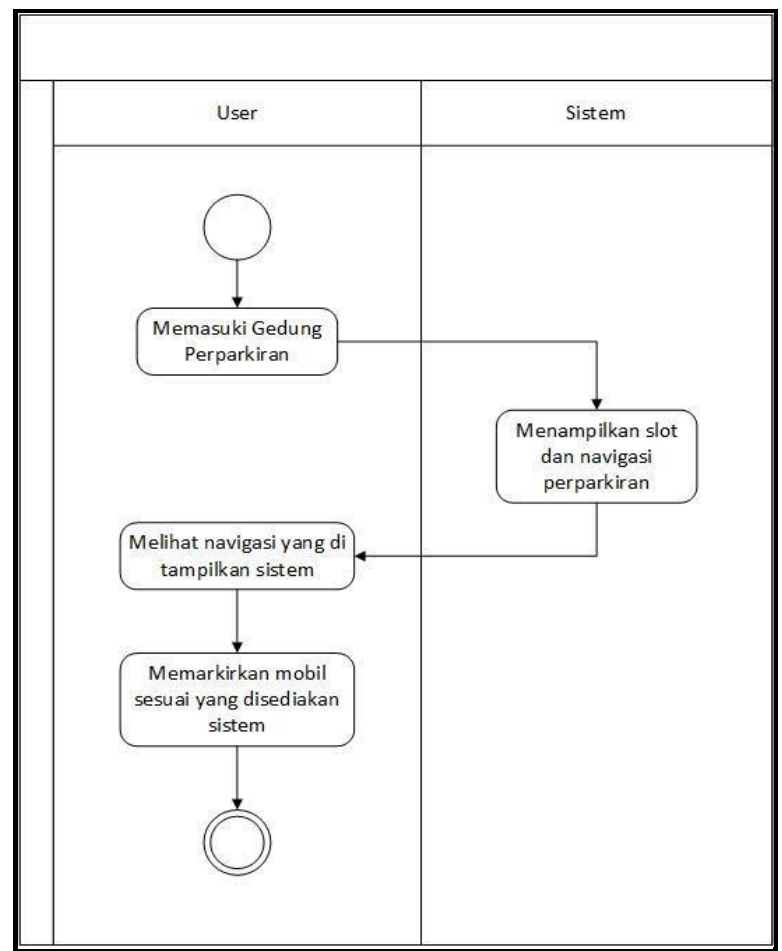

Gambar 9. Activity Diagram Memarkirkan Mobil 
4. Activity Diagram Melihat Navigasi

Untuk Activity diagram melihat navigasi digambarkan sebagai berikut :

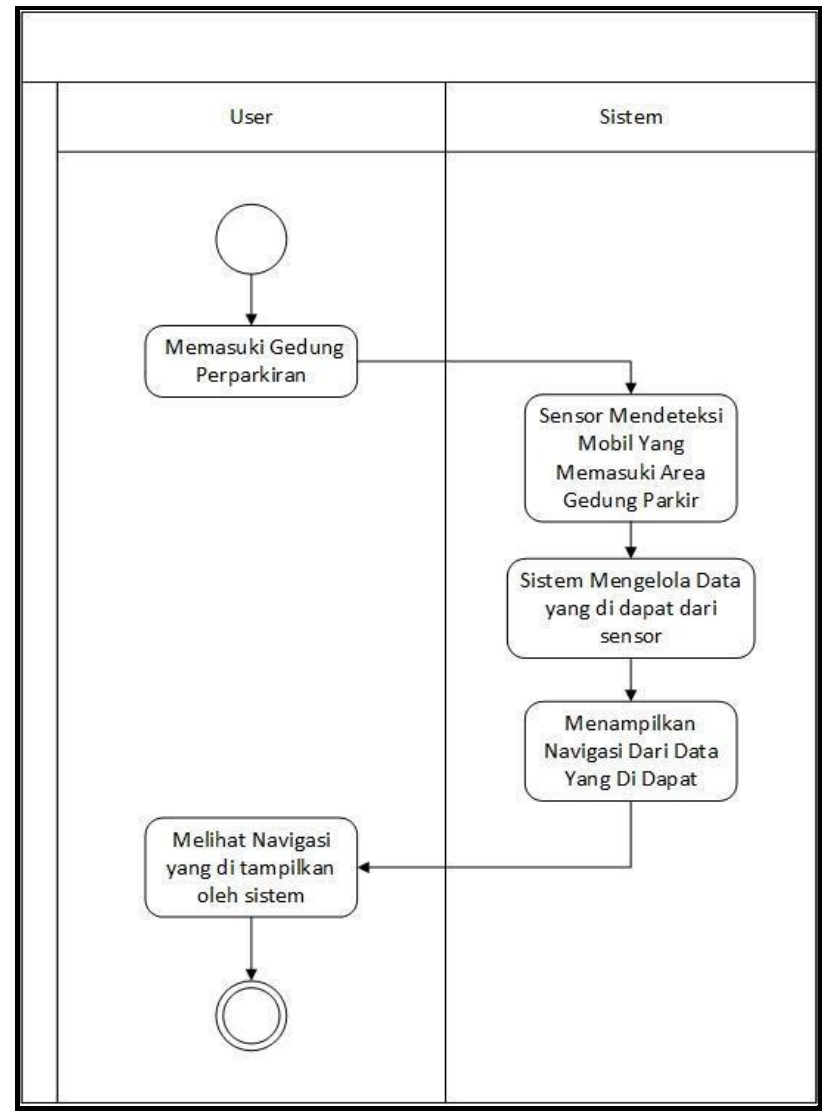

Gambar 10. Activity Diagram Melihat Navigasi

\section{KESIMPULAN}

Kesimpulan penelitian ini antara lain: Pembangunan desain arsitektur sistem parkir otomatis menggunakan mikrokontroler Arduino uno merupakan sistem yang digunakan untuk mencari tempat parkir secara otomatis menggunakan bantuan perangkat keras yang saling terintegrasi. Sistem ini dibangun menggunakan Arduino mikrokontroler dengan pemrograman Arduino IDE. Sistem ini membantu user untuk mencari tempat parkir yang paling terdekat dengan keadaan pengendara saat ini.dapat menjawab rumusan masalah saat ini berjalan dimana sistem mengelola data dengan sendiri nya untuk mendapatkan tempat parkir terdekat, sehingga sistem dapat menampilkan data tempat parkir yang kosong dan sudah terisi.Dengan dibangun sistem berbasis Arduino mikrokontroler dengan pemrograman Arduino IDE. Sistem ini membantu user dalam pengelolaan Parkiran.

\section{SARAN}

Disarankan agar menggunakan desain arsitektur sistem parkir otomatis berbasis Arduino Uno yang telah dibuat ini sebagai solusi mengatasi permasalahan yang terjadi saat ini serta dapat terus dikembangkan untuk dapat memberikan manfaat bagi Scientia Residences Tangerang. 


\section{DAFTAR PUSTAKA}

[1] FU'ADHILLAH AL'AMIN, 2019. PERANCANGAN MINIATUR SISTEM KONTROL PARKIR OTOMATIS BERBASIS PLC (PROGRAMMABLE LOGIC CONTROL), Vol 1, No 1, JURNAL ONLINE MAHASISWA (JOM). Universitas Pakuan

[2] Andi Idham Ramadhan,dkk. 2016, PENGEMBANGAN SISTEM PARKIR OTOMATIS MENGGUNAKAN ARDUINO MEGA 2560 BERBASIS, Vol 4, No 2, Jurnal Komputer dan Aplikasi, Universitas Tanjungpura.Pontianak.

[3] Muhammad Malikul,dkk. 2019, RANCANG BANGUN SISTEM PARKIR SECARA OTOMATIS DENGAN PENDETEKSI TANDA NOMOR KENDARAAN BERMOTOR BERBASIS PENGOLAHAN, Vol 3, No 2 , Jurnal TEKTRO.Teknik Elektro Politeknik Negeri Lhokseumawe

[4] Tsalis Faisal Amin,dkk. 2017, SISTEM PALANG PINTU PARKIR OTOMATIS TENAGA SURYA BERBASIS ARDUINO, Prosiding SEHATI, Vol 3 No 1. Fakultas Teknik Informatika, Universitas Islam Madura

[5] Arman Syah Putra, 2020. Analisa Dan Perancangan Sistem Tata Kelola Parkir Cerdas Di Kota Pintar Jakarta, Vol 4 No 3. Jurnal Komputer dan Informatika. STMIK Insan Pembangunan 